\title{
Roles sobre ruedas: Poder y estética a bordo de una combi
}

\author{
Julio César Mateus (Universidad de Lima, Perú)
}

Recibido 20/4/2007

Aprobado 25/5/2007

RESUMEN: El presente ensayo plantea una nueva aproximación al mundo de las combis, desde una perspectiva de análisis cultural. Propone ver a las combis más que como medios de movilidad urbana como productos culturales ricos en transacciones simbólicas. Indaga sobre las pugnas de poder libradas por sus usuarios, que adquieren nuevos roles y discursos. Además, se presentan diálogos multiculturales producidos desde la estética, los colores y la música. Se busca entregar una primera entrada en las combis como espacios de tensión donde se producen intrincados y novedosos efectos de sentido.

Palabras clave: Cultura popular - roles e identidades - medios de transporte productos culturales

\section{Roles on Wheels: Power and esthetics inside a "combi".}

SUMMARY: This essay studies the world of the "combis" (public transpiration vehicles that swarm Lima) in a new way, from a cultural perspective analysis. It consider "combis" not just as public transportation but as cultural products rich in symbolic transactions. Then, it explores struggle for power between the users, which end up getting new roles and discourses. Through observation, the esthetic produced by multicultural dialogs, the colors and the music start to appear. To sum it up, this articles primary goal is to deliver a new way to see "combis" as places were intricate and original sense effects take place. Key words: Popular culture - roles and identities - transport medium - cultural products 
॥ Incluso, antes de fundada, Lima nació combi", escribió el cronista Eloy Jáuregui parafraseando a Porras Barrenechea. Y razón le sobra. Combi es, pues, "la camioneta rural con ética asiática que conquistó el Perú antes que Fujimori, es el vehículo social de deslizamiento paulatino". ${ }^{1}$ Los limeños nos hacemos más limeños a bordo de estos carros de segunda mano, que son, más que sistemas de transporte público poco eficientes, espacios ricos en transacciones simbólicas, diálogos multiculturales y productos culturales interactivos que configuran roles sociales efímeros de estatus y poder y construyen nuevos modos de enunciación, al tiempo que pisan el acelerador recorriendo toda la ciudad.

Dentro de estos vehículos, las identidades parecen entenebrecerse. La hipótesis para que ello ocurra es que estos espacios se convierten, para los usuarios, en territorios ajenos, donde el ejercicio de los derechos se democratiza y opaca en función del nuevo lugar que se ocupa: el de un pasajero. Las combis limeñas son espacios de interacción, pero también feudos móviles donde los roles se resitúan o reacomodan.

\section{"Habla, ¿̇vas?": Identidades, roles y sujetos}

Hay tres sujetos protagonistas en la negociación que comprende el viaje en combi: el chofer, el cobrador y el usuario. El primero, dueño/responsable, por tanto, superior. El segundo, el operador logístico del negocio. De él depende en buena medida, por su vivacidad - o viveza, más bien - , cuánto será el ingreso diario, según la cantidad de pasajeros que logre (estratégicamente) acomodar dentro del vehículo y la astucia con que consiga sortear policías y señales de tránsito. También se encarga del "pago" a los "dateros", personajes ubicados en cada cierto tramo que indican las frecuencias y distancias entre las otras unidades de la ruta, y a quienes premia con 10 céntimos de sol cada pase. Según esta perspectiva, los subordinados vienen a ser los pasajeros, usuarios/clientes que en ejercicio forzoso o voluntario, abordan las combis con el fin de llegar, a falta de otro método, a sus destinos.

Desde esos distintos locus de enunciación, entendidos más que como espacios físicos, como ubicaciones construidas política y socialmente, es que se producen las negociaciones en el interior de una combi. La performance de los sujetos es percibida como normada de acuerdo con el nuevo escalafón en que se ubican, y no resulta extraño, por ello, la inédita configuración de poder a la que se adscriben de antemano. Como si el usuario, cualquiera sea su procedencia, su prosapia, su mérito o su familia fuera de la unidad

1 JÁUREGUI, Eloy. Usted es la culpable, 2004, p. 29. 
de transporte, dentro se sometiera a esta insubordinación simbólica presentada como trama novedosa de roles jamás evocados fuera de ella.

El cobrador, de educación básica o aun inconclusa, según empírica intuición, será quien indique/sugiera/ordene/disponga de las acciones en el interior, con el ánimo de salvaguardar su negocio, su billete, su chamba. Cual guardián, este sujeto, muy probable hijo o nieto de inmigrantes nacido en Lima, abrirá las puertas de su vehículo a quienes, voluntaria y selectivamente, desee. No obedeciendo un prurito caprichoso, en todo caso, sino una lógica liberal de ganancia (total, el consumidor es "libre" de optar por otro "servicio").

Cada usuario equivale, para él, el precio del pasaje que paga. Así, al escolar en mayor medida y un tanto menos al universitario, quienes según la ley deben pagar cantidades un poco menores que las ordinarias, les corresponderá un trato afín al desembolso que realizan para cubrir el costo de sus boletos. Hasta aquí una lógica comercial nada descabellada: mejor pago, mejor servicio. Desde su espacio de poder hegemónico, los cobradores los mandarán a sentarse al fondo, o ir parados, o los mirarán con cara de desprecio, no por haber tenido la suerte de estudiar algo que él tal vez quiso, sino por hacerle perder 20 céntimos de la ganancia del día. Otra opción es la de no permitir el acceso, sea porque el usuario reclama un trato más justo ("Oiga, pero si ya no hay asiento"... "Entonces tome taxi, pues, señora") o porque por su condición física (personas de avanzada edad o gente muy subida de peso) significará un retraso para que el vehículo llegue de acuerdo a lo "programado" - o a lo que dicte la circunstancia, para ser más realistas - al próximo paradero. Otra de sus prerrogativas es para con las damas que abordan la combi; si son de su gusto, se esforzará porque vayan cómodas y sin molestias de los demás pasajeros. De preferencia, las mujeres que reciben tan circunstancial deferencia responden al perfil de jóvenes "ricas y apretaditas".

Otra de las notorias tensiones a bordo de estas unidades es la pérdida de individualidad, en función de una adscripción colectiva. El usuario adquiere pertenencia al grupo de usuarios, se asocia a ellos. Todos, cualesquiera sean sus historias, forman, per se, parte del mismo gremio sojuzgado, del sindicato de usuarios que lucha por sus derechos ("Baje la velocidad, maestro"; "Detenga el carro para que suba la señora", "Trate bonito", "No sea abusivo"). Es consecuencia lógica por invadir un terreno ajeno, en el que nadie se siente cómodo, ni física ni psicológicamente. Es la consecuencia de la necesidad en su estado más puro. 


\section{"Avanza para atrás": Un ensayo de sociolecto urbano}

Desde el recordado Trampolín a la fa$m a$, programa de televisión del extinto animador Augusto Ferrando, donde concursaban inmigrantes, músicos populares (en su acepción más periférica) y personas de niveles socioeconómicos paupérrimos, no ha habido, con excepción de los viajes en combi, mejor oportunidad para los limeños de todas las condiciones y estratos de acercarnos al lenguaje popular. Las combis nos ofrecen crisoles léxicos maravillosos, espacios de reestructuración de lenguajes, tensiones y resistencias. Embarcarse en uno de estos vehículos es sumergirnos en un espacio simbiótico donde, desde el estibador del mercado de un distrito marginal hasta la señora con el pelo teñido de rubio cenizo en una peluquería bien, que regresa de comprar de su supermercado, deben pronunciar el célebre "Bajan semáforo" para descender en el lugar deseado. ¿Hay acaso algo más democrático?

Hay un metalenguaje que se cocina y fluctúa con la misma rapidez con que estos vehículos asiáticos transitan por las avenidas de nuestra gris megalópolis. Lo que se dice $-\mathrm{y}$ discute - en la combi es la institucionalización de la oralidad como lenguaje no oficial del limeño, con esos flujos y virajes súbitos, reapropiaciones transitorias y leves capturas que evidencian la errancia característica de las lenguas menores. ${ }^{2}$ Para subir a la combi hay que hablar combi: si no conjugas todos los verbos con una "s" al final, característica innata de un castellano marginal, ya "fuiste". Si te demoras en preguntar si esa línea pasa por la esquina de tu casa, también "fuiste". Solo en una combi se "avanza pa'trás" en vez de retroceder, se "pisa" para acelerar, el carro está "planchado" cuando está lleno y se "asencilla" para cambiar en monedas un billete. Pero no le discutas al cobrador, sigue avanzando para atrás, porque "al fondo siempre hay sitio".

Incluso las transacciones deben darse mediante el uso de este sociolecto. El usuario, al subir, podrá excepcionalmente negociar el precio del pasaje exclamando "china hasta el óvalo" (es decir, propondrá de manera explícita solo pagar la mitad del pasaje, china equivale a cincuenta céntimos), siempre que él y el cobrador consideren, de mutuo acuerdo, que el destino al que se dirige es relativamente corto. "No seas malo pues, varón" será la frase que se escucha en una combi si tal petición es denegada, cosa corriente ahora que el combustible se dispara - mortalmente, como

2 HEVIA GARRIDO-LECCA, Julio. Lenguas y devenires en pugna, 2002. 
las combis - y muchas han decretado que "la china ya murió, porque el petróleo la mató".

Para anunciar que uno ha llegado a su paradero ("avisando con tiempo por favor, señores") debe hacer uso del célebre "bajan semáforo". Ya no es "yo" el enunciatario sino "nosotros" -0 , lo que en la práctica resulta, "cualquiera de nosotros", "alguien de la masa", "un usuario más" - . El sujeto se ubica en la subordinada posición de quien no tiene el poder, representado en esa geografía por el chofer (con el timón como cetro), o su terrateniente, el cobrador.

Se produce, en la negociación descrita, un escenario de doble invasión. Por un lado, de la combi como elemento alterador de la estética hegemónica de la ciudad, y, al mismo tiempo, los usuarios, pertenecientes a esa primera instancia pero incorporados a una dinámica igualmente ajena que los obliga a adoptar una identidad fabricada y condicional. Es un proceso complejo de tensión dialógica por ambos lados.

\section{Gustos y sustos: Hacia una estética plural}

Provistas de una estética de evidente sinergia entre lo urbano y lo rural, las combis son, en mucha medida, vestigios reivindicatorios y anarquistas de sus dueños: pobladores de distritos marginales que, en carro propio o al- quilado, ingresan en una atmósfera ajena de ciudad - supuestamentemoderna. El contraste resulta rico y evidente: dentro del vehículo hay testimonios icónicos de una construcción aculturada de modernidad: stickers, $\mathrm{CD}$, luces sicodélicas, música potente, estampas religiosas; fuera de él, edificios, señales de tránsito, carteles publicitarios y un sinfín de elementos citadinos que prefiguran esa idea de intrusión. Como si las combis representaran vestigios de informalidad/ruralidad (usadas sensorialmente, desde el ethos cultural del usuario) dentro de un espacio distinto, más citadino y deseablemente "moderno".

La estética variopinta con que las combis son decoradas habla de valores simbólicos que trasuntan sentimientos, estados de ánimo y filosofías de vida: Juan ("sin apellido, hermanito") ha pagado para que le escriban con letras góticas "Guíame, Señor de Muruhuay" en la parte trasera de su carro, porque "es un cristo milagroso en quien mi viejita me enseñó a creer cuando vivíamos en Cora Cora". La historia se repite en muchos casos, incluso existe la versión en inglés "Guide Lord of Muruhuay". También tiene colgado en el espejo retrovisor un CD con un sticker del icono religioso en mención. "Más vale chola conocida que gringa con SIDA", se lee en una pegatina al lado del letrero de las tarifas, convenientemente ilegible - sobre todo donde dice cuánto cuesta el 
medio pasaje que, en teoría, pagan los estudiantes-. Respecto de este elemento, el tarifario, se produce otro efecto de tensión. Si bien este letrero da cuenta de los precios de los pasajes de forma "oficial" - sellado, firmado y sacramentado-, la dinámica combi no se fía de él para la negociación. El usuario ha aprendido que, por más legalidad que el negocio aparente, siempre todo es relativo y todo precio es susceptible de una "rebajita". Como cuando uno va a un mercado a comprar un kilo de papa amarilla y el "casero" (comprador) le pide a su "casero" (vendedor) - amén del tú a tú de los roles en ese proceso- "una rebajita". Igual en las combis, como si trasladáramos el ejercicio de compraventa a este gran puesto ambulante. Pocas son las veces en que el cobrador se referirá al tarifario como sustento de su reclamo. El poder se expresa, con más firmeza, abriendo la puerta del vehículo e invitando al pasajero a optar - "libremente" - por otra unidad... "Tome taxi, mejor".

"En recuerdo de mi madre Angustia Llacta", ha puesto Julián Rebasa en la puerta del vehículo de segunda mano que compró hace tres años, haciendo obvio honor a la memoria de su fenecida progenitora, que murió dos meses después de que Julián fuera dueño, por primera vez, de una combi. Al lado de un zapatito de cuerina que pende de su espejo y sobre la guantera (icono cabalístico repetido en camiones y taxis), ha pegado un colorido sticker con la cara de Condorito que dice: "En esta combi todo es bien chévere: la música, los pasajeros y el cobrador". Los colores fosforescentes de los carteles que anuncian los destinos y las rutas asemejan pancartas publicitando conciertos de Tongo en la Carretera Central, son préstamos de los colores usados para ciertas vestimentas serranas. Allí también se expresa esa sinergia.

Las combis "fiesteras", para ser consideradas como tales, deben tener un potente equipo estereofónico y luces, desde luego. No, no las luces regulares: luces de colores, incluso las navideñas sirven. Y si tienes esas "cortadoras" que se prenden cuando el carro frena, "tu combi es más pulenta" (moderna), señala Wálter, no sin antes advertir que el éxito está en la música que se ponga. Como aquí, en esta combi en la que estoy, en que suena al mediodía la estación popular Radio Inca Sat Turbo-Poder, anunciando con estridencia “... la fuerza, elegancia, experiencia, pasión de Dina (ina, ina, ina...) Páucar (áucar, áucar, áucar...) - cantante vernacular - en un único y espectacular concierto". Al parecer, la reina del folclor no las tiene todas consigo, pues la siguiente estación cuestiona las características antedichas; llama la señora Victoria, del Mercado Modelo, a manifestar su voto por Abencia Meza en este clásico de los clásicos, derbi del folclore: Aben- 
cia vs. Dina, en una maratónica competencia musical que viene durando casi media hora (y tres distritos) y no tiene visos de terminar. Un argumento contundente: Belén, de Carmen de la Legua, exige el hit "Mi taximoto" y también quiere mandar saludos a Gilbert y Pedro en el Mercado de Chorrillos. Batería electrónica y arpa andina, es el preludio, empieza el coro: Contenta paso la vida en mi taximoto, I llevando chicos muy lindos de paseo, / algunos me dicen 'a cincuenta, chinita' / otros me dicen 'chinita, una jaladita' / y otros me dicen 'negrita, te pago en mi casa'.

También las hay "criollas", "religiosas" $y$ "fichas" (con asientos forrados y sin tachones, casi nuevas). Pero, fuera de cualquier clasificación, ociosa de ensayar en estas líneas, las combis son representaciones híbridas que se presentan como espacios confusos, escandalosos, huachafos para la estética preadmitida de una ciudad moderna.

Las leyes, representadas por semáforos, señales de tránsito y agentes policiales, pueden/deben evadirse. Es una lucha contra un poder oficial y hegemónico - foucaultianamente entendido- y la reivindicación anarquista de la que hablábamos. El policía aparece como sujeto antagonista. $\mathrm{Su}$ figura desagrada, atemoriza o fastidia. Es la personificación del mundo de lo legal (aunque en la práctica no inspire el respeto que debiera, por razones ya conocidas).

El dueño de la combi - señor de su feudo - y su cobrador - terrateniente - pasan por la misma rutina de lunes a domingo (hasta el mediodía, eventualmente). Esperan ese domingo para regresar, para no salir de su espacio por un momento. Para no volver, invasores e intrusos, a esa Lima que se dice moderna y que sabe $y$ huele ajena. Se quedarán esas horas de descanso en una fiesta o pollada bailable, con potentes equipos estereofónicos. Equipos que adaptaron también en sus vehículos para resguardar su originalidad y para transformarlos en bastiones reminiscentes de su cultura y espacio, al que todos los usuarios, democráticamente, debemos subir para llegar a nuestro destino.

\section{Paradero final}

Las combis limeñas son presentadas como espacios de tensión donde los nuevos roles que se configuran en su interior, traen consigo intrincados y novedosos efectos de sentido. Si bien repasamos, como recorriendo avenidas, algunas señales trascendentes, quedan pendientes incursiones más profundas en cada una de las rutas planteadas: en la música, en la estética, en el lenguaje. Lo avanzado nos 
advierte que las combis son productos culturales complejos, productos - casi- de frontera, de debates que, lejos de contraponer lo oral contra lo escrito, lo rural contra lo urbano, lo formal contra lo informal, lo premoderno contra lo moderno, los tonifican. En suma, la combi propone un espacio de contraste y entrega a la reflexión, más que un souvenir al que habrá que tomarle fotos, otro esbozo de una sociedad en pugna permanente, $y$ una ciudad que hace de su indefinición un atractivo más de la ruta cultural de este país.

\section{Bibliografía}

HEVIA GARRIDO-LECCA, Julio. Lenguas $y$ devenires en pugna. Lima: Universidad de Lima, 2002. JÁUREGUI, Eloy. Usted es la culpable. Lima: Editorial Norma, 2004. 